of the incidence versus induction time curves, will shortly be published (Acta Path. et Microbiol. Scand.).

STMON IVERSEN

Fibiger Laboratory, University Institute of Pathological Anatomy, University of Copenhagen.

$$
\text { May } 27 .
$$

${ }^{1}$ Iversen, S., and Arley, N., Acta Path. et Microbiol. Scand., 27, 773 (1950). Arley, N., and Iversen, S., Acta Path. et Microbiol. Scand., 30, 21 (1952).

${ }^{2}$ Arley, N., and Iversen, S., Nature, 169, 410 (1952). Iversen, S., and Arley, N., Acta Path. et Microbiol. Scand., 31, 27 (1952).

- See references given in Blum, H. F., J. National Cancer Inst., 10, $463(1950)$.

\section{Crystal Structure of Histidine Hydrochloride Monohydrate}

Crystals of the hydrochloride monohydrate of the important amino-acid histidine can be obtained as rather thick tablets by evaporation of aqueous solutions containing a little hydrochloric acid. X-ray examination shows that the crystals are orthorhombic, with unit cell edges $a=15 \cdot 36 \mathrm{~A} ., b=8.92 \mathrm{~A}$. and $c=6.88 \mathrm{~A}$. The space group is $P 2_{1} 2_{1} 2_{1}$, and there are four molecules in the unit cell. The structure was obtained from a three-dimensional Patterson function which was interpreted by means of the vector convergence method ${ }^{1}$.

The atomic parameters as indicated by the vector convergence diagram were adjusted somewhat in order to improve the agreement of the calculated
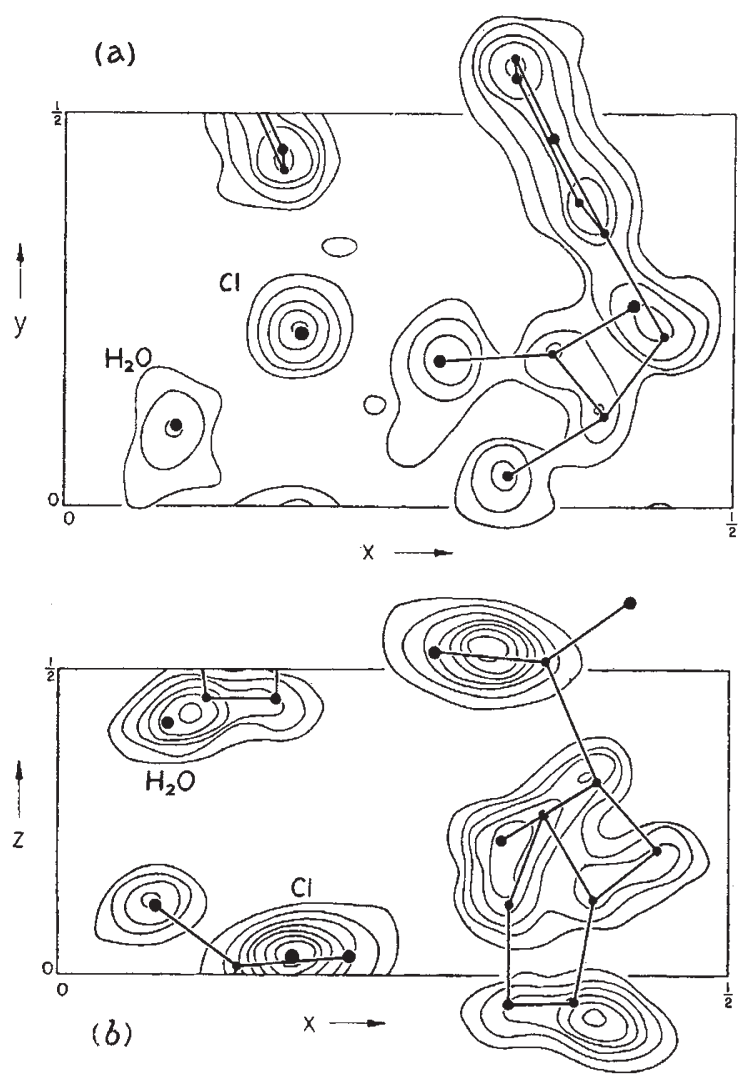

(a) Electron density projected down the c-axis; (b) electron density projected down the $b$-axis. Atomic positions, as obtained from the Patterson function, are shown by the solid circles interatomic vectors with observed Patterson peaks. The structure factors of the three prism zones were then calculated; the average discrepancy, $R$, for the 256 observed reflexions was 27 per cent. The structure factors of 170 of these reflexions were then treated by the method of least squares ${ }^{2}$. Shifts in the atomic parameters averaging $0.06 \mathrm{~A}$. were obtained.

Plots of the electron density projected down the $c$ - and $b$-axes were then prepared, by use of 89 of the 121 observed $(h k 0)$ reflexions and 57 of the 98 observed $(h 0 l)$ reflexions respectively. The resulting maps are reproduced herewith. Contours were drawn at equal arbitrary intervals, except about the chlorine atoms, where they are drawn at half that interval. The atomic shifts suggested by these plots are in fairly good agreement with those obtained from the least-squares treatment.

From the degree of resolution in these projections it is doubtful whether the structure in three dimensions could have been obtained from them alone. On the other hand, once having determined the structure from the Patterson function, it is probable that a satisfactory refinement can be achieved without recourse to laborious three-dimensional Fourier and least-squares analyses, which involve complex structure factors.

The parameter refinement has been temporarily postponed, and since at the present stage of the work the standard error in a parameter is about $005 \mathrm{~A}$., any discussion of the structure, such as which of the many tautomeric forms of the imidazole ring is present in the crystal, the precise dimensions of this heterocyclic ring, and the nature of the hydrogen bonding, must be deferred. At present, nevertheless, it is established that the histidine molecules in the crystal do not assume an extended configuration, but tend rather to curl back on themselves-a situation which may arise from significant attraction between the carboxyl group and the imidazole ring.

This work was carried out under Contract Nonr$220(05)$ with the Oftice of Naval Research.

JERRY DONOHUE

Gates and Crellin Laboratories of Chemistry, California Institute of Technology, Pasadena, California.

$$
\text { Oct. } 30 \text {. }
$$

1 Beevers, C. A., and Robertson, J. H., Acta Cryst, 3, 164 (1950).

a Hughes, E. W., J. Amer. Chrm. Soc., 63, 1737 (1941).

\section{Angle of Arrival of $Z$ Echoes}

IT has been suggested by Scott ${ }^{1}$ that uncoupled $F$-region $Z$ echoes are due to longitudinally propagated waves reflected from an area near the magnetic zenith.

Measurements of the angle of arrival of $Z$ echoes have recently been made at Hobart (geomagnetic latitude $51^{\circ} \mathrm{S}$., dip $72^{\circ}$ ) in order to test this suggestion. The mean direction was found to be in the magnetic plane $7 \cdot 8^{\circ}$ north of the vertical. Thirty-four measurements were made between July 13 and August 3, 1952 , on a frequency of $4.65 \mathrm{Mc} / \mathrm{s}$. In all cases the $Z$ echoes were observed during the late afternoon, the height of reflexion being between $170 \mathrm{~km}$. and $210 \mathrm{~km}$.

According to Scott's hypothesis, a collision frequency of about $1.5 \times 10^{5}$ por sec. would be needed to explain the observed angle. This is inconsistent with previous estimates of collision frequeney, which suggest that it is about $10^{4}$ per sec. at $200 \mathrm{~km}$. 